\title{
Prevalence and Intensity of Intestinal Helminth Infections in Preschool Pupils in Lugari Subcounty, Kakamega County, Kenya
}

\author{
Daniel Kevin Werunga $(\mathbb{D}$, Elizabeth Nanjala Omukunda $(\mathbb{D}$, and Jackson Cheruiyot Korir $(\mathbb{D}$ \\ Department of Biological Sciences, Masinde Muliro University of Science and Technology, P.O. Box 190, Kakamega, Kenya \\ Correspondence should be addressed to Daniel Kevin Werunga; kevin.werunga@gmail.com
}

Received 6 July 2020; Revised 14 October 2020; Accepted 22 October 2020; Published 7 November 2020

Academic Editor: María Eugenia López-Arellano

Copyright (C) 2020 Daniel Kevin Werunga et al. This is an open access article distributed under the Creative Commons Attribution License, which permits unrestricted use, distribution, and reproduction in any medium, provided the original work is properly cited.

\begin{abstract}
Intestinal helminths cause anaemia, malnutrition, indigestion disorders, retarded growth, and low mental abilities in pupils. About 1.5 billion are infected globally. Intestinal helminth infections are caused by Ascaris lumbricoides, Trichuris trichiura, Strongyloides stercoralis, Enterobius vermicularis, Ancylostoma duodenale, and Necator americanus. Lugari Subcounty has poor sanitation and inadequate clean water. This study determined the prevalence of intestinal helminth infections in preschool pupils in Lugari Subcounty. A stratified multistage cluster experimental design was used. Sampling was carried out in four wards: Lumakanda, Lugari, Luandeti, and Chekalini. Preschool pupils of either gender were selected randomly. Written consents and verbal assent were obtained from parents or guardians and preschool pupils, respectively. Questionnaires were administered in order to collect sociodemographic data. Stool samples were collected and tested for the presence of eggs using the standard Kato-Katz technique. Prevalence rate and prevalence ratio were calculated as the percentage of infected preschool pupils among the total number of preschool pupils examined. Preschool pupils positive with helminths were treated freely, and a follow-up screening was conducted three months after treatment. Approval of the study was sought from the Masinde Muliro University of Science and Technology Institutional Ethical Review Board (MMUST IRB). The overall prevalence of intestinal helminths was $12.3 \%$. Only one species, Ascaris lumbricoides, was identified. Statistical tests were carried out at a 5\% significance level $(p<0.05$, confidence interval (CI) 95\%). There was a statistically significant association for prevalence and intensity of intestinal helminths versus factors like school location, knowledge of washing hands before eating, and awareness of washing hands after visiting a toilet. Although this study revealed a low prevalence and light intensity, some factors had significant effects on intestinal helminth infections among the preschool children. Therefore, there is a need to intensify efforts for their intestinal helminth control.
\end{abstract}

\section{Introduction}

Over 270 million school pupils are located in regions with intensive intestinal helminthiases transmission, hence the need for protection, intervention, and treatment [1]. In Sub-Saharan Africa, it is estimated that about 1.98 billion individuals, including 40-50 million school-age pupils, are infected with intestinal helminths which results in a loss of about 7.5 million DALYs in the region against a global estimate of 22.1 million DALYs [2]. Primary pupils have the highest prevalence and infection intensities, and preschool pupils are likely to have as high infection rates of helminthiases as the primary pupils [3]. Kenya has more than 1.2 mil- lion pupils infected with intestinal helminths with 5 million at risk of infection. These infections are a salient public health problem among school pupils [4]. Intestinal helminthiases are common in developing countries and are of major health hazard because of their effect on the growth, development, nutritional, health, and immune status of the population [5-7]. Impacts on growth and development are common among pupils with heavier infections, whereas lighter infections may lead to stunted growth if the level of nutrition of the society is low [7] as a result of poor or nonabsorption of iron, potassium, and sodium ions in the body [8]. Intestinal helminths have been known to be the salient contributing factor of intestinal blood loss leading to iron deficiency and 
protein malnutrition [8]. Intestinal helminthiases are prevalent in most parts of Kenya with a variation in species distribution; for example, $N$. americanus is more prevalent at the coastal region of East Africa $[9,10]$. In Kenya, intestinal helminthiases are widely distributed with prevalence ranging from 12 to above $90 \%$ and have been linked to anaemia [11-13].

Several studies done in Busia district revealed intestinal helminth prevalences of $90 \%$ and above among school pupils with A. lumbricoides and T. trichiura being common [14, 15], thus the need to adopt the school-based approach for management and treatment of helminthiasis. In Bondo and Kisumu districts, helminthiasis prevalences of $12.3 \%$ and $12.9 \%$, respectively, [16, 17] were recorded. Kakamega County on the other hand recorded a higher prevalence of $43.5 \%$ [18]. Lugari Subcounty in Kakamega County in the Republic of Kenya has a large population of farmers who obtain domestic water from either rivers or wells. Shallow wells are the main source of water in the region. Some of these wells are covered while others are exposed, hence a risk for helminthiases. Majority of the preschool pupils come from low- to middle-income families and are likely to be exposed to intestinal helminthiases. Deworming programme was initiated as one of the control measures [19]. This study determined the prevalence and factors for intestinal helminth infections in preschool pupils in Lugari Subcounty.

\section{Materials and Methods}

2.1. Study Site. The study was carried out in Lugari Subcounty, a second-order administrative division located in Western Kenya $34^{\circ} 28^{\prime}$ to $35^{\circ} 00^{\prime}$ east and $0^{\circ} 25^{\prime}$ to $1^{\circ} 0^{\prime}$ north with an altitude of 1844 metres above sea level. It has a population of 215,920 and an area of $670 \mathrm{~km}^{2}$. Stratified multistage cluster design was used resulting into all the four wards of Lugari Subcounty: Lumakanda, Lugari, Luandeti, and Chekalini. All the four wards were picked for full representation. Preschool pupils were clustered according to sex, schools, wards, and environmental setup. Eight schools were chosen using the lottery method as suggested by the WHO guidelines [12]. Four schools were from the periurban setup and four from the rural setup. The sample size was determined according to Fox et al. [20]. The confidence level is $95 \%$ and precision of $5 \%$. The prevalence previously determined in Busia of $91.7 \%[14,20]$ was used to determine a sample size of 118 preschool pupils. However, 240 were recruited to take care of those who would likely drop out or fail to give a stool sample. There was a variation in the number of preschool pupils in different schools; thus, it was not possible to have a uniform number from each school. Therefore, all preschool pupils whose parents or guardians were willing to participate in the study were recruited.

2.2. Data Collection. Ethical approval was obtained from the Masinde Muliro University of Science and Technology Ethics Review Committee (MMU/COR: 403009(42)) and a research permit from the National Commission of Science, Technology and Innovation prior to the study (NACOSTI/P/16/92479/13634). Permission was sought from the county education and health offices. Finally, parents/guar- dians filled the informed consent forms before the commencement of the study. Pupils assented orally before the stool sample collection. Each participant and questionnaire was allocated a unique code for identification. Some of the questions asked including accessibility to latrine or toilet at home, a habit of hand washing after visiting latrine or toilet, were tackled by the respondents. Stool polypots were labelled with the unique code representing each of the participants. Stool samples were collected on a filter paper and transferred to labelled containers with the help of research assistants. The freshly collected stool samples were transported to the laboratory, approximately 50 kilometers (40 minutes of travelling) from the collection point, and examined on the same day of collection. Out of the original 204 participants who filled the questionnaire, 74 were not able to provide stool samples.

Only eggs were observed. Stool samples were processed according to the standard Kato-Katz method [21] in the laboratory by laboratory technologists and quality assurance by a senior laboratory technician, and results were recorded in a data sheet. The outcome of the stool was communicated to parents/guardians, and the provision of Albendazole by the study physician was made to pupils who tested positive.

2.3. Statistical Analysis. The coded data on the presence or absence of intestinal helminths in stool samples, number of eggs observed, and questionnaire was entered into the Microsoft Excel programme 2007 version and later imported into statistical software, STATISTICA 12. Prevalence ratio was used to calculate the strength of risk factors on infections of Ascaris lumbricoides. Prevalence ratios were calculated to relate the chances of infections with intestinal helminth according to Thompson, et al. [22]. Chi-square was run to determine the significant differences within variables, respectively [22]. Statistical tests were carried out at a 5\% significance level ( $p<0.05$, confidence interval (CI) 95\%). $p<0.05$ was regarded as statistically significant.

\section{Results}

3.1. Prevalence of Helminthic Parasites. Out of 218 selected respondents, $93.6 \%$ (204) participated in giving information on the assessment of risk factors and only 63.7\%(130) provided stool samples. Only Ascaris lumbricoides was present with a prevalence of $12.3 \%$ (Table 1). The results revealed that over fifty-five percent of the pupils, whose parents used water from uncovered wells and the river, were boys. Out of the 130 stool specimens obtained, $72.3 \%$ were from rural schools (Majengo, Sirende, Mapengo, and Chetambe) whereas $27.7 \%$ were from periurban schools (Lumakanda, Lugari, Musembe, and Maturu). Out of the 94 pupils in rural schools, $46.8 \%$ were boys and $53.2 \%$ were girls. Both boys and girls from the rural schools had an overall prevalence of $17 \%$ of $A$. lumbricoides. Girls had a prevalence of $14 \%$ of A. lumbricoides while boys had a prevalence of $20.5 \%$ of $A$. lumbricoides. The association between the prevalence of intestinal helminths and school location was statistically significant $(p=0.002)$. Out of the 36 pupils in periurban schools, $63.9 \%$ were boys and $36.1 \%$ were girls. None of the 
Table 1: Prevalence of Ascaris lumbricoides in preschool pupils.

\begin{tabular}{|c|c|c|c|c|c|c|}
\hline \multirow{2}{*}{ Primary school } & \multicolumn{3}{|c|}{ Total participants } & \multicolumn{3}{|c|}{ Prevalence of Ascaris lumbricoides } \\
\hline & Boys + girls & Boys & Girls & Boys + girls & Boys & Girls \\
\hline Rural schools & $64.6 \%(84 / 130)$ & $47.7 \%(40 / 84)$ & $52.3 \%(44 / 84)$ & $19 \%(16 / 84)$ & $22.5 \%(9 / 40)$ & $16 \%(7 / 44)$ \\
\hline Majengo & $9.2 \%(12 / 130)$ & $33.3 \%(4 / 12)$ & $66.7 \%(8 / 12)$ & $8.3 \%(1 / 12)$ & $25 \%(1 / 4)$ & 0 \\
\hline Sirende & $27.7 \%(36 / 130)$ & $52.8 \%(19 / 36)$ & $47.2 \%(17 / 36)$ & $30.6 \%(11 / 36)$ & $26.3 \%(5 / 19)$ & $35.3 \%(6 / 17)$ \\
\hline Mapengo & $9.2 \%(12 / 130)$ & $41.7 \%(5 / 12)$ & $58.3 \%(7 / 12)$ & 0 & 0 & 0 \\
\hline Chetambe & $18.5 \%(24 / 130)$ & $50 \%(12 / 24)$ & $50 \%(12 / 24)$ & $16.67 \%(4 / 24)$ & $25 \%(3 / 12)$ & $8.3 \%(1 / 12)$ \\
\hline Periurban schools & $35.4 \%(46 / 130)$ & $58.7 \%(27 / 46)$ & $41.3 \%(19 / 46)$ & 0 & 0 & 0 \\
\hline Lumakanda & $11.5 \%(15 / 130)$ & $80 \%(12 / 15)$ & $20 \%(3 / 15)$ & 0 & 0 & 0 \\
\hline Lugari & $11.5 \%(15 / 130)$ & $53.3 \%(8 / 15)$ & $46.7 \%(7 / 15)$ & 0 & 0 & 0 \\
\hline Musembe & $7.7 \%(10 / 130)$ & $40 \%(4 / 10)$ & $60 \%(6 / 10)$ & 0 & 0 & 0 \\
\hline Maturu & $4.6 \%(6 / 130)$ & $50 \%(3 / 6)$ & $50 \%(3 / 6)$ & 0 & 0 & 0 \\
\hline
\end{tabular}

boys or girls from the periurban schools was infected with $A$. lumbricoides as indicated in Table 1.

3.2. Risk Factors for the Prevalence of Ascaris lumbricoides. No intestinal helminth infections were registered in periurban schools. This may be because pupils from periurban schools are more exposed to information about helminths than their counterparts from rural schools. Prevalence ratios were used to establish the magnitude of various risk factors for intestinal helminth infections. The whole subcounty had a prevalence of $12.3 \%$ of $A$. lumbricoides in both boys and girls. Pupils who were not aware that they are supposed to wash hands before eating are 5 times more likely to be infected with intestinal helminths than pupils who knew. The pupils who did not have any type of toilet at home were 4 times more likely to be infected with intestinal helminths than pupils who have toilets at home. The low prevalence may be due to the fact that only $2 \%$ of the respondents did not have knowledge on the source of infection of intestinal helminths. About twenty percent of the respondents did not deworm their children. Pupils without knowledge of washing hands after visiting the toilet were 4 times more likely to be infected with intestinal helminths than pupils who were aware. Pupils who used water from the river, more than one source, springs, and pipes are 4, 3, 2, and 2 times more likely to be infected with intestinal helminths than those who used water from both covered wells and uncovered wells. The number of pupils with intestinal helminths was 3fold greater if a pupil used water that is not treated than those who used treated water.

Pupils who were dewormed at intervals of 3 and 6 months had equal chances of being infected with intestinal helminths. The number of intestinal helminth infections among pupils who were dewormed annually and those who were not dewormed was 5-fold and 4-fold greater than that of pupils who were dewormed at intervals of between 3 and 6 months (Figure 1).

Pupils who were 5 years old are $50 \%$ more likely to be infected with intestinal helminths than those who were 7 years old. Pupils who were 6 years old were $60 \%$ and were twice more likely to be infected with intestinal helminths than their colleagues who were 5 years and 7 years old,

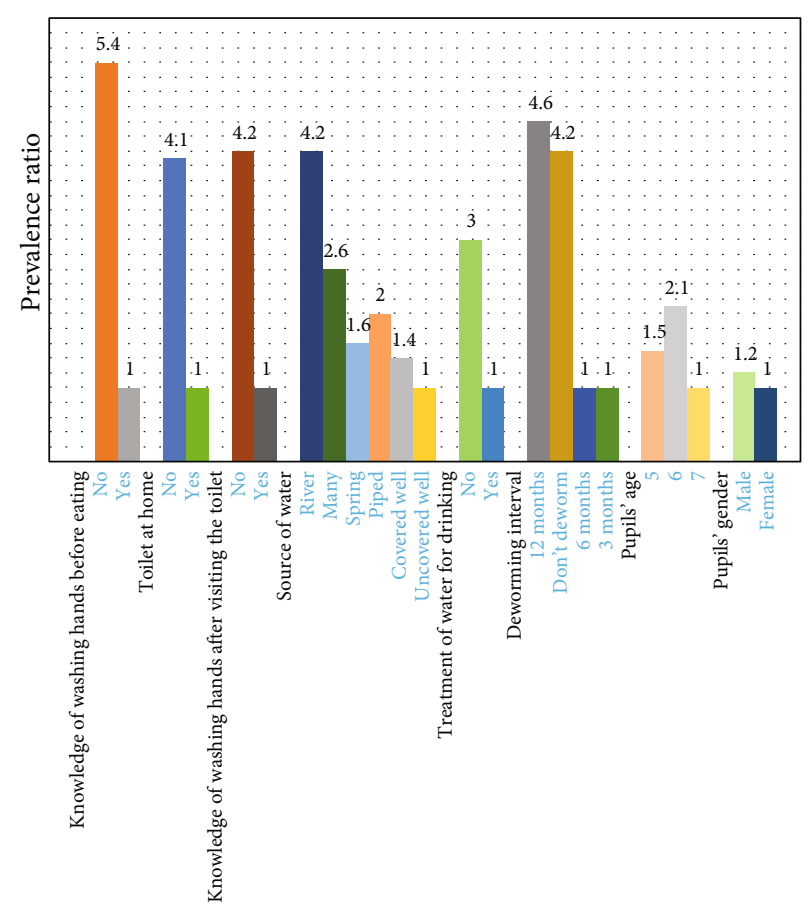

FIgURE 1: Association between prevalence and social factors that affect helminth infections.

respectively. The number of boys with intestinal helminths is $20 \%$ greater than girls (Table 2).

Graphical representation of the association between the prevalence of A. lumbricoides and socioeconomic factors is shown in Figure 1.

Using the Chi-square test, a statistically significant association was established between the prevalence of intestinal helminths and school location $\left(X^{2}(1, N=130)=9.992, p=\right.$ $0.002)$. The association was statistically significant between the prevalence of intestinal helminths and knowledge of washing hands before eating $\left(X^{2}(1, N=130)=15.331, p=\right.$ $0.001)$. A statistically significant association was established between the prevalence of intestinal helminths and awareness of washing hands after visiting the toilet $\left(X^{2}(1, N=130)=10.382, p=0.001\right)$. The following risk 
TABle 2: Association between different factors and prevalence of A. lumbricoides.

\begin{tabular}{|c|c|c|c|c|c|}
\hline \multirow[t]{2}{*}{ Variable } & \multicolumn{3}{|c|}{$\begin{array}{l}\text { A. lumbricoides } \\
\text { infection }\end{array}$} & \multirow[b]{2}{*}{ Ratio of infection } & \multirow{2}{*}{$\begin{array}{l}\text { Prevalence ratio } \\
\text { Ratio compared to the baseline group }\end{array}$} \\
\hline & Yes & No & Total & & \\
\hline \multicolumn{6}{|c|}{ Knowledge of washing hands before eating } \\
\hline No & 6 & 7 & 13 & $6 / 13=0.462$ & $0.462 / 0.085=5.4$ \\
\hline Yes & 10 & 107 & 117 & $10 / 117=0.085$ & $0.085 / 0.085=1$ \\
\hline \multicolumn{6}{|l|}{ Toilet at home } \\
\hline No & 3 & 4 & 7 & $3 / 7=0.429$ & $0.429 / 0.106=4.1$ \\
\hline Yes & 13 & 110 & 123 & $13 / 123=0.106$ & $0.106 / 0.106=1$ \\
\hline \multicolumn{6}{|c|}{ Knowledge of washing hands after visiting the toilet } \\
\hline No & 10 & 27 & 37 & $10 / 37=0.27$ & $0.270 / 0.065=4.2$ \\
\hline Yes & 6 & 87 & 93 & $6 / 93=0.065$ & $0.065 / 0.065=1$ \\
\hline \multicolumn{6}{|l|}{ Source of water } \\
\hline River & 8 & 26 & 34 & $8 / 34=0.235$ & $0.235 / 0.056=4.2$ \\
\hline Many & 1 & 6 & 7 & $1 / 7=0.143$ & $0.143 / 0.056=2.6$ \\
\hline Spring & 1 & 10 & 11 & $1 / 11=0.091$ & $0.091 / 0.056=1.6$ \\
\hline Piped & 1 & 8 & 9 & $1 / 9=0.111$ & $0.111 / 0.056=2$ \\
\hline Covered well & 4 & 46 & 50 & $4 / 50=0.08$ & $0.080 / 0.056=1.4$ \\
\hline Uncovered well & 1 & 17 & 18 & $1 / 18=0.056$ & $0.056 / 0.056=1$ \\
\hline \multicolumn{6}{|c|}{ Treatment of water for drinking } \\
\hline No & 11 & 45 & 56 & $11 / 56=0.196$ & $0.196 / 0.065=3$ \\
\hline Yes & 5 & 72 & 77 & $5 / 77=0.065$ & $0.065 / 0.065=1$ \\
\hline \multicolumn{6}{|l|}{ Deworming interval } \\
\hline 12 months & 6 & 19 & 25 & $6 / 25=0.24$ & $0.240 / 0.053=4.6$ \\
\hline Do not deworm & 6 & 21 & 27 & $6 / 27=0.222$ & $0.222 / 0.053=4.2$ \\
\hline 6 months & 1 & 18 & 19 & $1 / 19=0.053$ & $0.053 / 0.053=1$ \\
\hline 3 months & 3 & 52 & 55 & $3 / 55=0.055$ & $0.055 / 0.053=1$ \\
\hline \multicolumn{6}{|l|}{ Pupils' age } \\
\hline 5 & 6 & 40 & 46 & $6 / 46=0.13$ & $0.130 / 0.087=1.5$ \\
\hline 6 & 8 & 35 & 43 & $8 / 43=0.186$ & $0.186 / 0.087=2.1$ \\
\hline 7 & 2 & 21 & 23 & $2 / 23=0.087$ & $0.087 / 0.087=1$ \\
\hline \multicolumn{6}{|l|}{ Pupils' gender } \\
\hline Male & 9 & 58 & 67 & $9 / 67=0.134$ & $0.134 / 0.111=1.2$ \\
\hline Female & 7 & 56 & 63 & $7 / 63=0.111$ & $0.111 / 0.111=1$ \\
\hline
\end{tabular}

factors did not have a statistically significant association with the prevalence of intestinal helminths: method of faecal disposal, place of residence, source of water, water treatment method, deworming interval, pupils' age, and pupils' gender $\left(\left(X^{2}(3, N=130)=7.774, p=0.051\right),\left(X^{2}(1, N=130)=0.883\right.\right.$, $p=0.347), \quad\left(X^{2}(5, N=130)=5.705, \quad p=0.336\right)$, $\left(X^{2}(4, N=130)=6.343, p=0.175\right),\left(X^{2}(4, N=130)=9.454\right.$, $p=0.051), \quad\left(X^{2}(4, N=130)=4.407, \quad p=0.354\right), \quad$ and $\left(X^{2}(1, N=130)=0.162, p=0.687\right)$, respectively (Table 3$\left.)\right)$.

3.3. Intensity of Helminthic Parasites. The intensity of infection for intestinal helminths was calculated by multiplying the number of observed eggs of $A$. lumbricoides by 24 to give eggs per gram of faeces (EPG) based on the WHO [23] grouping system of intestinal helminth infection intensities [24]. The intensity of infection was expressed as the mean eggs per gram of faeces (EPG). There were no stool samples from preschool pupils with more than 50000 EPG of A. lumbricoides, and therefore, heavy intensity was not encountered in the study site.

Out of the 16 study participants who tested positive with Ascaris lumbricoides at the subcounty level, two participants who had egg counts of 5000-49999 EPG were grouped under moderate intensity, and fourteen samples with 1-4999 EPG were grouped under light intensity as shown in Table 4.

Both boys and girls had an average egg count of 4498 EPG (light intensity). Out of the 9 infected boys, 8 had light 
TABLE 3: Association between prevalence and risk factors.

\begin{tabular}{|c|c|c|c|}
\hline Variable & +ve $\%(n / 16)$ & -ve $\%(n / 114)$ & Chi $p$ value \\
\hline \multicolumn{4}{|l|}{ School location } \\
\hline Periurban & 0 & $40.4 \%(46)$ & $0.002^{*}$ \\
\hline Rural & $100 \%(16)$ & $59.6 \%(68)$ & \\
\hline \multicolumn{4}{|l|}{ Place of residence } \\
\hline Rural & $100 \%(16)$ & $94.7 \%(108)$ & 0.347 \\
\hline Urban & 0 & $5.3 \%(6)$ & \\
\hline \multicolumn{4}{|c|}{ Knowledge of washing hands before eating } \\
\hline Yes & $62.5 \%(10)$ & $107(93.9 \%)$ & $0.001^{*}$ \\
\hline No & $37.5 \%(6)$ & $6.1 \%(7)$ & \\
\hline \multicolumn{4}{|l|}{ Faecal disposal } \\
\hline Pit latrine & $81.3 \%(13)$ & $86 \%(98)$ & \\
\hline Flush toilet & 0 & $9.6 \%(11)$ & 0.051 \\
\hline Flush \& pit & 0 & $0.9 \%(1)$ & \\
\hline Bush & $18.7 \%(3)$ & $3.5 \%(4)$ & \\
\hline \multicolumn{4}{|c|}{ Knowledge of washing hands after visiting the toilet } \\
\hline Yes & $37.5 \%(6)$ & $76.3 \%(87)$ & $0.001^{*}$ \\
\hline No & $62.5 \%(10)$ & $23.7 \%(27)$ & \\
\hline \multicolumn{4}{|l|}{ Source of water } \\
\hline River & $8(50 \%)$ & $22.8 \%(26)$ & \\
\hline Piped water & $6.3 \%(1)$ & $7 \%(8)$ & \\
\hline Uncovered well & $6.3 \%(1)$ & $14.9 \%(17)$ & 0.336 \\
\hline Covered well & $25 \%(4)$ & $40.4 \%(46)$ & \\
\hline Many & $6.3 \%(1)$ & $5.3 \%(6)$ & \\
\hline Spring water & $6.3 \%(1)$ & $8.8 \%(10)$ & \\
\hline \multicolumn{4}{|c|}{ Method of treating water for drinking } \\
\hline Sieving & $43.8 \%(7)$ & $29.8 \%(34)$ & \\
\hline Chemical & $18.8 \%(3)$ & $46.5 \%(53)$ & \\
\hline Boiling & $12.5 \%(2)$ & $14 \%(16)$ & 0.175 \\
\hline Many & 0 & $2.6 \%(3)$ & \\
\hline Do not treat & $25 \%(4)$ & $9.6 \%(11)$ & \\
\hline \multicolumn{4}{|l|}{ Deworming interval } \\
\hline 3 months & $18.8 \%(3)$ & $45.6 \%(52)$ & \\
\hline 6 months & $6.3 \%(1)$ & $15.8 \%(18)$ & \\
\hline 12 months & $37.5 \%(6)$ & $16.7 \%(19)$ & 0.051 \\
\hline Do not deworm & $37.5 \%(6)$ & $18.4 \%(21)$ & \\
\hline Uncertain & 0 & $3.5 \%(4)$ & \\
\hline \multicolumn{4}{|l|}{ Pupils' age } \\
\hline 5 & $37.5 \%(6)$ & $35.1 \%(40)$ & \\
\hline 6 & $50 \%(8)$ & $30.7 \%(35)$ & \\
\hline 7 & $12.5 \%(2)$ & $18.4 \%(21)$ & 0.354 \\
\hline 8 & 0 & $9.6 \%(11)$ & \\
\hline 9 & 0 & $6.1 \%(7)$ & \\
\hline \multicolumn{4}{|l|}{ Pupils' gender } \\
\hline Male & $56.25 \%(9)$ & $50.9 \%(58)$ & 0.687 \\
\hline Female & $43.75 \%(7)$ & $49.1 \%(56)$ & \\
\hline
\end{tabular}

${ }^{*}$ Significant variables at 0.05 . intensity and only 1 had moderate intensity. All the boys had an average egg count of 4234 EPG (light intensity). Out of the 7 infected girls, 6 had light intensity and 1 had moderate intensity. All the girls had an average of 4838 EPG (light intensity). Although both boys and girls had light intensity, the latter had a slightly higher average egg count. Nonetheless, the association between intensity of intestinal helminths and gender was not statistically significant $(p=0.906)$.

3.4. Risk Factors for Intensity of Ascaris lumbricoides. For factors affecting intensity of intestinal helminths, a statistically significant association was observed between intensity of intestinal helminths and factors like school location, knowledge of washing hands before eating, and awareness of washing hands after visiting the toilet as determined by Chi-square.

There was no statistically significant association between intensity of intestinal helminths for residence, method of faecal disposal, source of water, method of treating water for drinking, deworming interval, pupils' age, and pupils' gender as determined by Chi-square (Table 5 ).

\section{Discussion}

4.1. Prevalence of Ascaris lumbricoides in Lugari Subcounty. The overall prevalence of intestinal helminths observed in the current study population was very similar to that of Odiere and Odhiambo [16] in Kisumu, Western Kenya. The findings of the prevalence of intestinal helminths of the study are consistent with two similar studies carried out in Bondo district, western part of Kenya [17] and Sudan [25] in Southern Sudan that showed a prevalence of $12.9 \%$ and $12.3 \%$, respectively. This was linked to geographical variations and socioeconomical and hygienic conditions of the population under consideration. The present study results are almost like a recent study carried out in three subcounties: KakamegaCentral, Kakamega-South, and Kakamega-East by Ngojo et al. [18]. In their study, A. lumbricoides was the most prevalent with a higher prevalence of $43.5 \%$ [18].

The low prevalence in the current study might be a result of school intestinal helminth prevention programmes by deworming. It is also likely that the environment is less contaminated, and the preschool pupils had knowledge on hand washing after using the toilet especially in the urban setting. Most urban schools have water with detergent provided for use outside the latrines. The absence of hookworms could be because the third larval stage has a lower life expectancy (3-10 days) unlike A. lumbricoides eggs that have several months of infective period [15]. There was a prevalence of 4.9\% for A. lumbricoides and $7.7 \%$ for T. trichiura [16], and in a number of studies, A. lumbricoides infections were more prevalent than other intestinal helminths like T. trichiura and hookworms [26]. Moreover, T. trichiura eggs last for a shorter time in the soil than those of A. lumbricoides because they are very sensitive to desiccation because they do not have a thick sticky albumin coating that would make them adhere to different surfaces. They are easily swept away or washed to lower layers due to their smooth surface coating [27]. 
Table 4: Intensity of Ascaris lumbricoides Lugari Subcounty.

\begin{tabular}{|c|c|c|c|c|c|c|c|c|c|}
\hline \multirow{2}{*}{ Classification strata and categories } & \multicolumn{3}{|c|}{ Total cases in boys } & \multicolumn{3}{|c|}{ Total cases in girls } & \multicolumn{3}{|c|}{ Total cases in boys + girls } \\
\hline & Light & Moderate & Heavy & Light & Moderate & Heavy & Light & Moderate & Heavy \\
\hline \multicolumn{10}{|l|}{ (1) Schools } \\
\hline Majengo & 1 & 0 & 0 & 0 & 0 & 0 & 0 & 0 & 0 \\
\hline Sirende & 4 & 1 & 0 & 5 & 1 & 0 & 9 & 2 & 0 \\
\hline Chetambe & 3 & 0 & 0 & 1 & 0 & 0 & 4 & 0 & 0 \\
\hline \multicolumn{10}{|l|}{ (2) Wards } \\
\hline Lumakanda & 1 & 0 & 0 & 0 & 0 & 0 & 1 & 0 & 0 \\
\hline Lugari & 4 & 1 & 0 & 5 & 1 & 0 & 9 & 2 & 0 \\
\hline Luandeti & 3 & 0 & 0 & 1 & 0 & 0 & 4 & 0 & 0 \\
\hline (3) Overall & 8 & 1 & 0 & 6 & 1 & 0 & 14 & 2 & 0 \\
\hline
\end{tabular}

Low prevalences of A. lumbricoides of $4.6 \%, 16.2 \%$, $12.4 \%$, and $8.7 \%[3,16,26]$, respectively, have been reported from Western Kenya in the recent past compared to earlier studies where the prevalence was as high as $42.5 \%$ [28]. This is evident that the school deworming programme which was effected in Kenya in 1998 is effective [29, 30]. Multiple infections of intestinal helminths were not observed in this study which is a significant observation, and it could be credited to the impact of the school-based adopted control programme. Also, low prevalence of A. lumbricoides could be due to community access to improved hygiene practices as well as improved health service delivery. Generally, hookworms have a slower rate of infections compared to $A$. lumbricoides.

Studies on intestinal helminth infection prevalence from endemic countries indicate that ascariasis is more prevalent as compared to other intestinal helminths [31]. In this study, the prevalence of ascariasis was slightly more in boys than girls, but it was not statistically significant contrary to a study in Nigeria that indicated that it was [31]. This can be attributed to the fact that boys do participate in more outdoor activities like playing football with bare feet. This makes boys more infected than their female counterparts. However, another study [32] revealed an observation contrary to such findings where intestinal helminth infections were more common in females than in males.

Preschool children living near the river presented with higher prevalence of $A$. lumbricoides infections compared to children living in residential areas away from the river. Although there is no study that links intestinal helminth infections with closeness to the river, lowlands and upland tend to show differences in intestinal helminth infections [27]. This can be due to rain water carrying infected soil from other areas to the lowlands. The use of water from the river may increase infections further as observed in Colombia, with a trend in prevalence ranging between $0.6 \%$ and $2.4 \%$ for A. lumbricoides [33].

4.2. Risk Factors for the Prevalence of Ascaris lumbricoides in Lugari Subcounty. The Chi-square test revealed that the relationship between the prevalence of intestinal helminths and school location was statistically significant. To be precise, all the positive cases were from rural schools. The finding is not strange because poor hygiene and lack of piped water and other sanitary facilities in the rural area are strong determinants of high prevalence of intestinal helminths in rural schools [34]. The association between the area of residence and intestinal helminth infections was not statistically significant. In another study, intestinal helminths were found common in rural areas due to poor living conditions, lack of information about helminths, and poor sanitation $[35,36]$. However, in the present study, a good number of individuals in rural areas practice hygienic standards.

Pupils who were not aware that they were supposed to wash hands before eating were 5 times more likely to be infected with intestinal helminths than pupils who knew. There was a statistically significant association between intestinal helminth infections and knowledge about washing hands before eating. Over $60 \%$ of the infected children did not know that they were supposed to wash hands before eating. However, over 30\% knew that they were supposed to wash hands before eating. Although the questionnaire did not test the knowledge of using soap to wash hands before eating, the difference may be due to the fact that those who knew that they were supposed to wash hands did not use detergents or soap. It is also likely that they used untreated or contaminated water to wash their hands leading to intestinal helminth infections because persons who washed hands without soap had 2.6 times likelihood of being infected with $A$. lumbricoides compared with individuals who used soap.

The pupils who did not have any type of toilet at home were 4 times more likely to be infected with intestinal helminths than pupils who had toilets at home. The association between the prevalence of intestinal helminths and techniques of faecal disposal was not statistically significant. All the positive cases either relieved themselves in pit latrines and the bush. This study is in consonance with previous studies which showed that child latrine use is associated with intestinal helminth infections [21, 37]. Pupils who used pit latrines had $68.8 \%$ while those who used flush toilets had $12.5 \%$ of the positive cases. Interestingly, pupils who did not have any toilet or relieved themselves in the bush had $18.8 \%$ positive cases. That implied that despite the lack of latrine being one of the risk factors that expose children to A. lumbricoides, hygienic practices and other factors 
TABLE 5: Association between intensity and risk factors.

\begin{tabular}{|c|c|c|c|}
\hline Variable & Infected & Not infected & $p$ value \\
\hline \multicolumn{4}{|l|}{ School location } \\
\hline Periurban & 0 & $46 / 114(40.4 \%)$ & $0.007^{*}$ \\
\hline Rural & $16 / 16(100 \%)$ & $68 / 114(59.6 \%)$ & \\
\hline \multicolumn{4}{|l|}{ Place of residence } \\
\hline Rural & $16 / 16(100 \%)$ & $108 / 114(94.7 \%)$ & 0.643 \\
\hline Urban & 0 & $6 / 114(5.3 \%)$ & \\
\hline \multicolumn{4}{|c|}{ Knowledge of washing hands before eating } \\
\hline Yes & $10 / 16(62.5 \%)$ & $107 / 114(93.9 \%)$ & $0.001^{*}$ \\
\hline No & $6 / 16(37.5 \%)$ & $7 / 114(6.1 \%)$ & \\
\hline \multicolumn{4}{|l|}{ Faecal disposal } \\
\hline Pit latrine & $13 / 16(81.3 \%)$ & $98 / 114(86 \%)$ & \\
\hline Flush toilet & 0 & $11 / 114(9.6 \%)$ & 0.154 \\
\hline Flush \& pit & 0 & $1 / 114(0.9 \%)$ & \\
\hline Bush & $3 / 16(18.7 \%)$ & 4/114 (3.5\%) & \\
\hline \multicolumn{4}{|c|}{ Knowledge of washing hands after visiting the toilet } \\
\hline Yes & $6 / 16(37.5 \%)$ & $87 / 114(76.3 \%)$ & $0.003^{*}$ \\
\hline No & $10 / 16(62.5 \%)$ & $27 / 114(23.7 \%)$ & \\
\hline \multicolumn{4}{|l|}{ Source of water } \\
\hline River & $8 / 16(50 \%)$ & $26 / 114(22.8 \%)$ & \\
\hline Piped water & $1 / 16(6.3 \%)$ & 8/114 (7\%) & \\
\hline Uncovered well & $1 / 16(6.3 \%)$ & $17 / 114(14.9 \%)$ & 0.299 \\
\hline Covered well & $4 / 16(25 \%)$ & $46 / 114(40.4 \%)$ & \\
\hline Many & $1 / 16(6.3 \%)$ & $6 / 114(5.3 \%)$ & \\
\hline Spring water & $1 / 16(6.3 \%)$ & $10 / 114(8.8 \%)$ & \\
\hline \multicolumn{4}{|c|}{$\begin{array}{l}\text { Method of treating water for } \\
\text { drinking }\end{array}$} \\
\hline Sieving & $7 / 16(43.8 \%)$ & $34 / 114(29.8 \%)$ & \\
\hline Chemical & $3 / 16(18.8 \%)$ & $53 / 114(46.5 \%)$ & \\
\hline Boiling & $2 / 16(12.5 \%)$ & $16 / 114(14 \%)$ & 0.427 \\
\hline Many & 0 & $3 / 114(2.6 \%)$ & \\
\hline Do not treat & $4 / 16(25 \%)$ & $11 / 114(9.6 \%)$ & \\
\hline \multicolumn{4}{|l|}{ Deworming interval } \\
\hline 3 months & $3 / 16(18.8 \%)$ & $52 / 114(45.6 \%)$ & \\
\hline 6 months & $1 / 16(6.3 \%)$ & $18 / 114(15.8 \%)$ & \\
\hline 12 months & $6 / 16(37.5 \%)$ & $19 / 114(16.7 \%)$ & 0.161 \\
\hline Do not deworm & $6 / 16(37.5 \%)$ & $21 / 114(18.4 \%)$ & \\
\hline Uncertain & 0 & $4 / 114(3.5 \%)$ & \\
\hline \multicolumn{4}{|l|}{ Pupils' age } \\
\hline 5 & $6 / 16(37.5 \%)$ & $40 / 114(35.1 \%)$ & \\
\hline 6 & $8 / 16(50 \%)$ & $35 / 114(30.7 \%)$ & \\
\hline 7 & $2 / 16(12.5 \%)$ & $21 / 114(18.4 \%)$ & 0.522 \\
\hline 8 & 0 & $11 / 114(9.6 \%)$ & \\
\hline 9 & 0 & $7 / 114(6.1 \%)$ & \\
\hline \multicolumn{4}{|l|}{ Pupils' gender } \\
\hline Male & $9 / 16(56.25 \%)$ & $58 / 114(50.9 \%)$ & 0.906 \\
\hline Female & $7 / 16(43.75 \%)$ & $56 / 114(49.1 \%)$ & \\
\hline
\end{tabular}

*Significant variables at 0.05 . contribute to a high prevalence among pupils who use pit latrines [38].

Pupils who were not aware that they were supposed to wash hands after visiting the toilet were 4 times more likely to be infected with intestinal helminths than pupils who were aware. The association between the prevalence of intestinal helminths and awareness that one is supposed to wash hands after visiting the toilet was statistically significant. More of the infected children did not know that they were supposed to wash hands after visiting the toilet. This implies that improper hygienic practices like failure to wash hands after visiting the toilet could be the probable cause of autoinfection. Proper washing of hands after visiting the toilet can lower the risk of intestinal helminth infection by minimizing the shedding of helminth eggs into the surrounding environment, leading to reduced transmission [39].

Pupils who used water from both covered and uncovered wells were less likely to be infected than those who used water from the river, springs, and pipes. The number of pupils with intestinal helminths is 3 -fold greater if a pupil uses water that is not treated than that who uses treated water. There was no statistically significant relationship between the prevalence of intestinal helminth infections and sources of water. This does not agree with other studies which indicated that intestinal helminth infections are high in children who drink unsafe water as compared to those who drink safe water [40]. More than a half of the pupils with intestinal helminth infections came from families in which people use river as a source of water which is a well-documented risk factor for intestinal helminth infections [5]. When water from wells and rivers comes in contact with overflowing drains and waste water or with open defecation, optimum conditions for the growth and development of the ova of $A$. lumbricoides are provided which lead to spreading of intestinal helminths especially $A$. lumbricoides [41].

The number of pupils with intestinal helminths was 3 times greater if a pupil used untreated water than the one who used treated water. This study confirms that the relationship between the prevalence of intestinal helminths and methods of treating water for drinking is not significant. This contradicts a study in Uganda which showed that failure to treat water before use can contribute to increased intestinal helminth infections [42]. However, treatment of domestic water has a positive impact on the prevalence of intestinal helminths [5]. This finding can be attributed to the fact that infections cut across board among children whose parents/guardians treat water and those who do not treat.

Pupils who were dewormed at intervals of 3 to 6 months had equal chances of being infected with intestinal helminths. The number of intestinal helminth infections among pupils who were dewormed annually and those who were not dewormed is 5 -fold and 4 -fold (respectively) greater than that of pupils who were dewormed at intervals of between 3 and 6 months. The current study confirms that the association between the prevalence of intestinal helminths and intervals of deworming is not statistically significant. Deworming on a regular basis has been effective in lowering intestinal helminth infections in a cost-efficient way because antihelminthic drugs can reduce the transmission of 
intestinal helminth infections by reducing worm load and production of intestinal helminth eggs $[43,44]$.

Pupils who were 5 years old were $50 \%$ more likely to be infected with intestinal helminths than those who were 7 years old. Pupils who were 6 years old were $60 \%$ and twice more likely to be infected with intestinal helminths than their counterparts who were 5 and 7 years old, respectively. Although the association between age and prevalence of intestinal helminth infections was not statistically significant, at 5,6 , and 7 years old, there were $37.5 \%, 50 \%$, and $12.5 \%$ of the positive cases, respectively. Above 8 years of age, no pupil was infected with intestinal helminths. Younger children are not grown enough to participate in more outdoor activities. Studies show that as children grow, there is an increased trend in the involvement of more outdoor activities. This can lead to increased prevalence up to around a certain age at which the children gain knowledge about hygienic practices. Some may become less active, hence a decrease in the prevalence of intestinal helminths [45]. The number of boys with intestinal helminths was $20 \%$ greater than that of girls. Despite the fact that the relationship between the prevalence of intestinal helminths and gender was not statistically significant, boys had a slightly higher prevalence than girls. This finding does not agree with a past investigation which indicated that girls are more vulnerable to intestinal helminthiasis than boys [32].

4.3. Intensity of Ascaris lumbricoides in Lugari Subcounty. Most of the infected preschool children had a light to moderate infection intensity of $A$. lumbricoides infections. This difference may be due to increased reinfection in girls because $11.1 \%$ of the parents/guardians to girls had not heard about intestinal helminthiasis compared to $3 \%$ of parents/guardians to boys. Another reason could be the fact that $12.7 \%$ of the girls did not know that hands should be washed before eating compared to only $7.5 \%$ of their male counterparts. Additionally, over a third of the girls were not aware that they were required to wash hands after visiting the toilet compared to only a quarter of boys. Also, $12.7 \%$ of the parents/guardians to girls were not aware of deworming programmes compared to $6 \%$ of parents/guardians to boys. The last reason could be because $25.4 \%$ of the girls were not dewormed compared to $16.4 \%$ of the boys. Other studies have also concluded that girls have a higher average intensity, compared to their boy counterparts [46].

Although both boys and girls had light intensity, the latter had a slightly higher average egg count. Although the intensity was generally low, $24.5 \%$ of the participants only sieved water before drinking and $14.7 \%$ of them indicated that they did not treat or sieve water, but they instead use it directly. If no action is taken, this can increase the rate of infection which might lead to higher intensities of intestinal helminths in the future.

4.4. Risk Factors for the Intensity of Ascaris lumbricoides in Lugari Subcounty. The association between intensity of intestinal helminths and method of faecal disposal was not statistically significant. This is not a surprise because about $90 \%$ of the positive cases were recorded among children who use pit latrines and those who do it in the bush. Inadequate latrine access and improper use of the same can contribute to a high intensity of intestinal helminths $[47,48]$.

The association between intensity of intestinal helminths and deworming intervals was not statistically significant. People who dewormed their children once a year and those who did not deworm constituted $75 \%$ of the total infections. Regular deworming is known to reduce the transmissibility of intestinal helminths by reducing worm load and production of eggs [44].

The association between intensity of intestinal helminths and school location was statistically significant. All the positive cases were from rural schools. Lack of clean water and proper health amenities in rural areas are good indications of a high intensity of intestinal helminths [34]. These results are similar to a past study which concludes that residence and intensity of intestinal helminths are related due to features of the environment like unclean water [49].

The intensity of intestinal helminth infections and methods of treating water for drinking are not statistically significant, $70 \%$ of the positive cases comprised of those who failed to treat. Untreated water increases the intensity of intestinal helminths [5].

The association between intensity of intestinal helminths and awareness of washing hands before eating was statistically significant. Not all the preschool pupils who were aware that they were required to wash hands actually implemented the knowledge. Also, it seems that those who practiced hand washing did not do it properly. Research shows that correct washing of hands with appropriate detergents, after defecation or before meals, can lead to a decreased intensity of intestinal helminth infections [45].

The relationship between intensity of intestinal helminths was statistically significant. Despite the fact that both boys and girls had an average of light intensity, the latter had a slightly higher egg count than the former. This is consistent with another study which concluded that girls have a higher average intensity compared to their boy counterparts [50].

The association between intensity of intestinal helminths and awareness of washing hands before eating was statistically significant. This agrees with a study carried out in Western Uganda [50] which concluded that awareness of washing hands after visiting the toilet is one of the factors associated with intensity of intestinal helminths.

This study revealed a statistically insignificant association between intensity of intestinal helminths and residence. This agrees with the study done in Thika, Central Kenya [18], where intensity of intestinal helminth infection was significantly associated with area of residence. In the study, intensity was significantly high in rural residence. Although the differences were not statistically significant in the current study, light to moderate intensity was recorded from pupils in rural residence while no single infection was recorded from pupils who stayed in urban areas.

Intensity of intestinal helminths and sources of water were not statistically significantly associated. This observation contradicts another study [28] that concluded that intensity of intestinal helminth infections was significantly different in individuals using different sources of water. 
The association between intensity of intestinal helminths and pupils' age is statistically insignificant. This contradicts a study in Tanzania [51] which indicated that intensity of intestinal helminths was significantly different among age groups.

\section{Conclusion}

Although a low prevalence light intensity was observed and only one species, Ascaris lumbricoides, was identified in this study, the prevalence of A. lumbricoides among preschool pupils was significantly associated with the method of faecal disposal, school location, awareness that one is supposed to wash hands before eating, source of water, and deworming interval. We recommend that stool collection to be done during different seasons. Although the Kato-Katz method is a fast method, researchers should consider other techniques because Kato-Katz is less sensitive [52, 53]. Thus, more efforts should be made to educate the preschool pupils and parents/guardians to avoid the build-up of the parasitic load in the environment to achieve zero helminthiases in the country.

\section{Data Availability}

Due to the sensitive nature of the questions asked in this study, survey respondents were assured raw data would remain confidential and would not be shared.

\section{Conflicts of Interest}

The authors declare that they have no conflicts of interest.

\section{Acknowledgments}

We are grateful to the National Commission for Science, Technology and Innovation for funding this research (reference number: NACOSTI/RCD/ST and I/7th CALL/Msc/161). We also recognize the assistance by the Public Health Office of Lugari Subcounty, Mr. Peter K. Nyongesa, and Mr. Simon Sakwa from the Masinde Muliro University Biological Sciences Department, in addition to all the supporting field work health officers from the area of for their contribution during this research period. Our sincere gratitude also goes to the preschool pupils, together with their guardians or parents, for their role of making the exercise successful.

\section{References}

[1] WHO, Soil-transmitted helminth infections. Fact sheet, PLoS ONE, 2017.

[2] J. Bethony, S. Brooker, M. Albonico et al., "Soil-transmitted helminth infections: ascariasis, trichuriasis, and hookworm," The Lancet., vol. 367, no. 9521, pp. 1521-1532, 2006.

[3] A. Obala, C. Simiyu, D. Odhiambo et al., "Survey of soil transmitted helminthes and intestinal protozoa among children up to five years," Journal of Tropical Medicine, vol. 10, 330 pages, 2013.
[4] J. C. Uneke, "Soil transmitted Helminth infections and schistosomiasis in school age children in Sub-Saharan Africa: efficacy of chemotherapeutic intervention since World Health Assembly Resolution 2001," Tanzania Journal of Health, vol. 12, no. 1, pp. 86-99, 2010.

[5] J. Alli, I. Okonko, O. Alabi et al., "Parasitological evaluation of some vended sachet water in Southwestern Nigeria," New York Science Journal, vol. 4, no. 10, pp. 84-92, 2011.

[6] P. J. Hotez, D. A. Bundy, K. Beegle et al., "Helminth infections: soil-transmitted helminth infections and schistosomiasis," in Disease Control Priorities in Developing Countries, The International Bank for Reconstruction and Development/The World Bank, 2nd edition, 2006.

[7] K. Ziegelbauer, B. Speich, D. Mäusezahl, R. Bos, J. Keiser, and J. Utzinger, "Effect of sanitation on soil-transmitted helminth infection: systematic review and meta-analysis," PLoS Medicine, vol. 9, no. 1, article e1001162, 2012.

[8] D. H. Molyneux, P. J. Hotez, and A. Fenwick, “"Rapid-impact interventions": how a policy of integrated control for Africa's neglected tropical diseases could benefit the poor," PLoS Medicine, vol. 2, no. 11, article e336, 2005.

[9] R. W. Ashford, P. S. Craig, and S. J. Oppenheimer, "Polyparasitism on the Kenya coast. 2. Spatial heterogeneity in parasite distributions," Annals of Tropical Medicine \& Hygiene, vol. 87, no. 3, pp. 283-293, 2016.

[10] P. Hotez, P. Brindley, J. Bethony, C. King, E. Pearce, and J. Jacobson, "Helminth infections: the great neglected tropical diseases," Journal of Clinical Investigation, vol. 118, no. 4, pp. 1311-1321, 2008.

[11] H. L. Guyatt, S. Brooker, C. M. Kihamia, A. Hall, and D. A. Bundy, "Evaluation of efficacy of school-based anthelmintic treatments against anaemia in children in the United Republic of Tanzania," Bulletin of the World Health Organization, vol. 79, no. 8, pp. 695-703, 2001.

[12] A. Koukounari, B. B. Estambale, J. K. Njagi et al., "Relationships between anaemia and parasitic infections in Kenyan schoolchildren: a Bayesian hierarchical modelling approach," International Journal for Parasitology, vol. 38, no. 14, pp. 1663-1671, 2008.

[13] P. Magnussen, "Treatment and re-treatment strategies for schistosomiasis control in different epidemiological settings: a review of 10 years' experiences," Acta Tropica, vol. 86, no. 2-3, pp. 243-254, 2003.

[14] M. Booth, B. J. Vennervald, L. Kenty et al., "Micro-geographical variation in exposure to Schistosoma mansoni and malaria, and exacerbation of splenomegaly in Kenyan school-aged children," BMC Infectious Diseases, vol. 4, no. 1, p. 13, 2004.

[15] S. Brooker, A. C. A. Clements, and D. A. P. Bundy, "Global Epidemiology, ecology and control of soil-transmitted Helminth infections," Advances in Parasitology, vol. 62, pp. 221-261, 2006.

[16] M. R. Odiere, S. Opisa, G. Odhiambo et al., "Geographical distribution of schistosomiasis and soil-transmitted helminths among school children in informal settlements in Kisumu City, Western Kenya," WGZO Parasitology, vol. 138, no. 12, pp. 1569-1577, 2011.

[17] F. W. Thiong'o, A. Luoba, and J. H. Ouma, "Intestinal helminths and schistosomiasis among school children in a rural district in Kenya," East African Medical Journal, vol. 78, no. 6, pp. 279-282, 2001.

[18] W. T. Ngonjo, H. J. Kihara, M. Gicheru, P. Wanzala, M. S. Njenga, and S. C. Mwandawiro, "Prevalence and intensity of 
intestinal parasites in school age children in Thika District, Kenya," African Journal of Health Sciences, vol. 21, pp. 153160, 2012.

[19] D. O. Mokua, R. S. Shivairo, C. Muleke, D. K. Mukabane, M. O. Oswe, and J. Kumba, "Soil transmitted helminthes prevalence among pre-school age children in Elburgon municipality, Kenya," Journal of Biology, Agriculture and Healthcare, vol. 4, pp. 36-41, 2014.

[20] N. Fox, A. Hunn, and N. Mathers, Sampling and Sample Size Calculation, The NIHR RDS for the East Midlands/Yorkshire \& the Humber, Yorkshire, 2007.

[21] E. C. Strunz, D. G. Addiss, M. E. Stocks, S. Ogden, J. Utzinger, and M. C. Freeman, "Water, sanitation, hygiene, and soiltransmitted helminth infection: a systematic review and metaanalysis," PLoS Medicine, vol. 11, no. 3, p. e1001620, 2014.

[22] M. L. Thompson, E. J. Myers, and D. Kriebel, "Prevalence odds ratio or prevalence ratio in the analysis of cross sectional data: what is to be done?," Occupational and Environmental Medicine, vol. 55, no. 4, pp. 272-277, 1998.

[23] WHO, Schistosomiasis and soil-transmitted helminth infections- preliminary estimates of the number of children treated with albendazole or mebendazole, soil-transmitted helminth infections: updating the global picture, Weekly Epidemiological Record, 2006.

[24] T. W. Mwangi, J. M. Bethony, and S. Brooker, "Malaria and helminth interactions in humans: an epidemiological viewpoint," Annals of Tropical Medicine \& Parasitology, vol. 100, no. 7, pp. 551-570, 2006.

[25] J. Magambo, E. Zeyhle, and T. M. Wachira, "Prevalence of intestinal parasites among children in southern Sudan," East African Medical Journal, vol. 75, no. 5, pp. 288-290, 1998.

[26] M. R. Odiere, F. O. Rawago, M. Ombok et al., "High prevalence of schistosomiasis in Mbita and its adjacent islands of Lake Victoria, western Kenya," Parasites \& Vectors, vol. 5, no. 1, p. 278, 2012.

[27] A. I. Luoba, P. W. Geissler, B. Estambale et al., "Earth-eating and reinfection with intestinal helminths among pregnant and lactating women in western Kenya," Tropical Medicine and International Health, vol. 10, no. 3, pp. 220-227, 2005.

[28] T. Handzel, D. Karanja, D. Addiss et al., "Geographic distribution of schistosomiasis and soil-transmitted helminths in Western Kenya: implications for anthelminthic mass treatment," The American Journal of Tropical Medicine and Hygiene, vol. 69, no. 3, pp. 318-323, 2003.

[29] J. Bethony, J. Chen, S. Lin et al., "Emerging Patterns of Hookworm Infection: Influence of Aging on the Intensity ofNecatorInfection in Hainan Province, People's Republic of China," Clinical Infectious Diseases, vol. 35, no. 11, pp. 13361344, 2002.

[30] S. Brooker, A. Jardim-Botelho, R. J. Quinnell et al., “Agerelated changes in hookworm infection, anaemia and iron deficiency in an area of high Necator americanus hookworm transmission in South-Eastern Brazil," Transactions of the Royal Society of Tropical Medicine and Hygiene, vol. 101, no. 2, pp. 146-154, 2007.

[31] O. A. Adefioye, A. M. Efunshile, O. Ojurongbe et al., "Intestinal helminthiasis among school children in Ilie, Osun State, Southwest, Nigeria," Sierra Leone Journal of Biomedical Research, vol. 3, no. 1, pp. 36-42, 2011.

[32] E. A. Kenyong and J. E. Eyo, "Prevalence of intestinal helminths infections among school children in tropical semi urban communities," Animal Research International, vol. 5, no. 1, pp. 804-810, 2009.

[33] A. L. Londoño, S. Mejia, and J. E. Gomez-Marín, "Prevalencia y Factores de Riesgo Asociados a Parasitismo intestinal en Preescolares de Zona Urbana en Calarcá, Colombia," Revista de Salud Pública, vol. 11, no. 1, pp. 72-81, 2009.

[34] A. Abossie and M. Seid, "Assessment of the prevalence of intestinal parasitosis and associated risk factors among primary school children in Chencha town, Southern Ethiopia," BMC Public Health, vol. 14, no. 1, p. 166, 2014.

[35] O. O. Omitola, H. O. Mogaji, A. S. Oluwole, A. A. Adeniran, O. M. Alabi, and U. F. Ekpo, "Geohelminth infections and nutritional status of pre-school aged children in a periurban settlement of Ogun State," Scientifica, vol. 2016, Article ID 7897351, 9 pages, 2016.

[36] F. M. Ukoli, Prevention and Control of Parasitic Diseases in Tropical Africa: The Main Issues, University Press, 1992.

[37] H. M. Al-Mekhlafi, J. Surin, A. Atiya, W. Ariffin, and M. A. Mohammed, "Pattern and predictors of soil-transmitted helminth reinfection among aboriginal schoolchildren in rural Peninsular Malaysia," Acta Tropica, vol. 107, no. 2, pp. 200 204, 2008.

[38] J. Benjamin-Chung, A. Nazneen, A. Halder, R. Haque, A. Siddique, and M. Uddin, "The interaction of deworming, improved sanitation, and household flooring with soiltransmitted helminth infection in rural Bangladesh," PLoS Neglected Tropical Diseases, vol. 9, no. 12, article e0004256, 2015.

[39] M. C. Freeman, T. Clasen, S. J. Brooker, D. O. Akoko, and R. Rheingans, "The impact of a school-based hygiene, water quality and sanitation intervention on soil-transmitted helminth reinfection: a cluster-randomized trial," The American Journal of Tropical Medicine and Hygiene, vol. 89, no. 5, pp. 875-883, 2013.

[40] O. Alver, Y. Heper, I. Ercan, H. Akalın, and O. Touml, "Prevalence of intestinal parasites in Bursa Province of Turkey and assessment of enzyme-linked immunosorbent assays (ELISA) and three microscopic methods in the diagnosis of Entamoeba histolytica/Entamoeba dispar," African Journal of Microbiology Research, vol. 5, no. 12, pp. 1443-1449, 2011.

[41] S. Awasthi, T. Verma, P. V. Kotecha, V. Venkatesh, V. Josh, and S. Roy, "Prevalence and risk factors associated with worm infestation in pre-school children (6-23 months) in selected blocks of Uttar Pradesh and Jharkhand, India," Indian Journal of Medical Sciences, vol. 62, no. 12, pp. 484-491, 2008.

[42] R. Dumba, J. B. Kaddu, and F. W. Mangen, "Intestinal helminths in Luweero district, Uganda," African Health Sciences, vol. 8, no. 1, pp. 90-96, 2008.

[43] B. Phommasack, K. Saklokham, C. Chanthavisouk, V. Nakhonesid-Fish, and H. Strandgaard, "Coverage and costs of a school deworming programme in 2007 targeting all primary schools in Lao PDR," Transactions of the Royal Society of Tropical Medicine and Hygiene, vol. 102, no. 12, pp. 12011206, 2008.

[44] WHO, Prevention and control of schistosomiasis and soiltransmitted helminthiasis: report of a WHO expert committee, World Health Organization, 2002.

[45] T. Shumbej, T. Belay, Z. Mekonnen, T. Tefera, and E. Zemene, "Soil-transmitted helminths and associated factors among preschool children in Butajira Town, South-Central Ethiopia: a community-based cross-sectional Study," PLoS One, vol. 10, no. 8, article e0136342, 2015. 
[46] P. Kirwan, S. Asaolu, S. Molloy, T. Abiona, A. Jackson, and C. Holland, "Patterns of soil-transmitted helminth infection and impact of four-monthly albendazole treatments in preschool children from semi-urban communities in Nigeria: a double-blind placebo-controlled randomised trial," BMC Infectious Diseases, vol. 9, no. 1, p. 1, 2009.

[47] I. Ali, G. Mekete, and N. Wodajo, "Intestinal parasitism and related risk factors among students of Asendabo elementary and junior secondary school, southwestern Ethopia," Ethopian Journal of Health Development, vol. 13, no. 2, pp. 157-161, 1999.

[48] A.-M. M. Hesham, J. Surin, A. Atiya, W. Ariffin, and M. A. Mohammed, "Pattern and predictors of soil-transmitted helminth reinfection among aboriginal schoolchildren in rural Peninsular Malaysia," Acta Tropica, vol. 107, no. 2, pp. 200204, 2008.

[49] S. Knopp, K. Mohammed, I. Khamis, A. Mgeni, and J. Stothard, "Spatial distribution of soil-transmitted helminths, including Strongyloides stercoralis, among children in Zanzibar," Geospatial Health, vol. 3, no. 1, pp. 47-56, 2008.

[50] S. Ojja, S. Kisaka, M. Ediau et al., "Prevalence, intensity and factors associated with soil-transmitted helminths infections among preschool-age children in Hoima district, rural western Uganda," BMC Infectious Diseases, vol. 18, no. 1, pp. 408-412, 2018.

[51] M. Mugono, E. Konje, S. Kuhn, J. Mpogoro, and H. D. Mazigo, "Intestinal schistosomiasis and geohelminths of Ukara Island, North-Western Tanzania: prevalence, intensity of infection and associated risk factors among school children," Parasites \& Vectors, vol. 7, no. 1, p. 612, 2014.

[52] I. D. Amoah, G. Singh, T. A. Stenstrom, and P. Reddy, "Detection and quantification of soil-transmitted helminths in environmental samples: a review of current state-of-the-art and future perspectives," Acta Tropica, vol. 169, pp. 187-201, 2017.

[53] P. Cools, J. Vlaminck, M. Albonico et al., "Diagnostic performance of a single and duplicate Kato-Katz, Mini-FLOTAC, FECPAKG2 and qPCR for the detection and quantification of soil-transmitted helminths in three endemic countries," PLoS Neglected Tropical Diseases, vol. 13, no. 8, article e0007446, 2019. 